\title{
Comportamentos de Fair Play e Antiesportivos: Avaliação dos Árbitros
}

Fair Play and Unsporting Behavior: Evaluation of Referees

Comportamientos de Fair Play y No-deportivos: Evaluación del Juez

\author{
Marcella Andressa Bosquetti ${ }^{1}$, Amanda Oliveira de Morais ${ }^{2}$, Leandro Altimari ${ }^{3}$, Silvia Regina de Souza ${ }^{4}$
}

\begin{abstract}
[1-4] Universidade Estadual de Londrina I Título abreviado: Comportamentos de Fair Play | Endereço para correspondência: Departamento de Psicologia Geral e Análise do Comportamento, Universidade Estadual de Londrina. Rod. Celso Garcia Cid, Km 380, Campus Universitário. Caixa Postal 10011, CEP 86057-970, Londrina, PR, Brasil. I Email: marcellabosquetti@hotmail.com I DOI: 10.18761/pac.2015.6.1.a05
\end{abstract}

Resumo: Objetivou-se investigar comportamentos de fair play e antiesportivos em jogos de futsal das categorias Sub 9 e Sub 15, por meio da avaliação dos árbitros. Participaram 17 árbitros que apitaram jogos da $1^{\text {a }}$ divisão de um campeonato de futsal em uma cidade do Paraná. Ao final de cada partida os árbitros respondiam a Ficha de Avaliação de Fair Play, que era composta por seis questões referentes à atuação dos técnicos, atletas e a própria atuação. A ficha avaliava, por meio de uma escala de 0-10, o quanto a atuação dos participantes havia sido esportiva ou antiesportiva. Os dados obtidos foram avaliados comparando-se a atribuição de notas entre as categorias observadas, entre as questões e entre as categorias e as súmulas das partidas. Análises estatísticas sugerem que há diferenças significativas referente à esportividade entre as categorias, sendo a Sub 9 a que, na opinião dos árbitros, apresentou mais comportamentos de fair play. Com relação à atribuição de notas, a análise estatística apontou para a não existência de correlação entre as notas atribuídas e a quantidade de faltas e cartões durante as partidas. Com base nos resultados obtidos e na escassez de trabalhos realizados sobre fair play com árbitros sugere-se investigações futuras.

Palavras-chave: psicologia do esporte, futsal, categorias de base, árbitros

Abstract: This study aimed to investigate fair play behaviors and anti-sports in futsal games Sub 9 and Sub 15 categories, through the referees' evaluation. Participated 17 referees who refereed games in $1^{\circ}$ division of a futsal championship in a Paranás city. At the end of each match referees answered to Fair Play Assessment Record, which was composed of six questions related to the actions of coaches, athletes and his or her own activities. The Assessment Recorded, through a scale of $0-10$, how the performance of the participants had been sporting or unsportsmanlike. The data were evaluated by comparing the grading between categories observed, between questions and between the categories and the dockets of matches. Statistical analysis suggests that there are significant differences on the sportsmanship between the categories, the Sub 9 that, in the opinion of the referees, showed more behaviors of fair play. With regard to grading, the statistical analysis pointed to the lack of correlation between the marks awarded and the amount of fouls and cards during matches. Based on the results achieved and the lack of studies conducted on fair play with referees future researches are suggested.

Keywords: sport psychology, futsal, base categories, referees 
Resumen: Este estudio tuvo como objetivo investigar las conductas de juego limpio y antiesportivos en los juegos de fútbol sala de las categorías Sub 9 y Sub15, a través de la evaluación de los jueces. Los participantes fueron 17 jueces que arbitraron partidos en la $1^{\text {a }}$ división de un campeonato de fútbol sala en Paraná. Al final de cada juego, los jueces respondieron a Declaración de Evaluación de Juego Limpio, que se compone de seis preguntas relacionadas con las acciones de los entrenadores, atletas y jueces. El registro fue mediante una escala de 0 a 10, de cómo el desempeño de los participantes había sido deportivo o antideportivo. Los datos fueron evaluados mediante la comparación de la clasificación entre las categorías observadas, entre las cuestiones y entre las categorías y los resúmenes de los partidos. El análisis estadístico sugiere que existen diferencias significativas en la deportividad entre las categorías, la Sub 9 que, en opinión de los jueces, mostró un comportamiento de juego limpio. En la clasificación, el análisis estadístico se refirió a la falta de correlación entre las puntuaciones otorgadas y la cantidad de faltas y tarjetas durante los partidos. Con base en los resultados obtenidos sugieren futuras investigaciones.

Palabras-clave: psicología del deporte, fútbol sala, categorías básicas, jueces 
O interesse por questões relacionadas à ética e a moral no esporte aumentou nas últimas décadas, principalmente em razão de sua inserção na formação educacional de crianças e jovens (Estrada, González-Mesa, \& Méndez, 2007; Weiss, Smith, \& Stuntz, 2008). Da perspectiva educacional esportiva, os programas de iniciação deveriam se preocupar tanto com o ensino das habilidades específicas de uma modalidade quanto com os comportamentos considerados morais para a cultura na qual estão inseridos (Mazo, 2011; Santos, 2005).

Educadores como Thomas Arnold e Pierre de Coubertin defendem o esporte como contexto positivo e apropriado para ensinar o fair play (jogo limpo), o que contribuiria para a educação social e moral dos jovens de forma geral, por meio do desenvolvimento de habilidades de cooperação, enfrentamento de estresse, tolerância à frustração e atraso de recompensas (Cruz, Boixadós, Valiente, Torregrosa, \& Mimbrero, 1996; Del Pozo, 2007). Por outro lado, autores como Pilz (1995), afirmam que a prática esportiva tem favorecido o jogo enganoso e agressivo, principalmente em função da vitória como objetivo a qualquer custo. Para a maioria dos pesquisadores na área, contudo, o esporte não é por si só, contexto positivo ou negativo para o desenvolvimento de comportamentos de fair play, mas sim um contexto neutro (Cruz et al. 1996; Del Pozo, 2007; Weiss et al., 2008). Ressalta-se que sua conotação positiva ou negativa dependerá da orientação dos organizadores de competições e de outras pessoas importantes envolvidas nesse contexto, como, treinadores, pais, amigos e o público em geral e, ainda, do desenvolvimento de atividades apropriadas que permitam a identificação de modelos de regras adequadas, que reforcem comportamentos pró-sociais, discutam diferentes perspectivas e falem das vantagens desses momentos de ensino (Weiss et al. 2008). Adicionalmente, o estudo de Estrada et al. (2007) demonstrou que a participação de jovens atletas em esportes de contato intermediário (basquete e futebol) afeta as opiniões sobre os comportamentos e atitudes de fair play no contexto esportivo, sugerindo possível influência da modalidade esportiva nos comportamentos de fair play.

Alguns pesquisadores afirmam que há de fato uma crença generalizada de que a esportividade está se deteriorando cada vez mais nas competições infantis, local onde deveria ser promovida (Cruz et al.,1996; Del Pozo, 2007). Uma das hipóteses levantadas pelos pesquisadores é a de que muitos programas de iniciação esportiva copiam o modelo do esporte profissional que valoriza demasiadamente a vitória. Por conta disso, há uma preocupação de alguns psicólogos do esporte, principalmente nos Estados Unidos, Inglaterra (Graziano, 1978; Kavussanu \& Boardley, 2009; Weiss et al. 2008) e na Espanha (Cruz et al. 1996; Del Pozo, 2007; Gimeno, Sáenz, Ariño, \& Aznar, 2007) com o fato de o contexto esportivo possibilitar ou prejudicar o desenvolvimento de comportamentos de fair play.

A ideia de fair play faz parte da ética esportiva e está ligada à noção de moralidade. A partir de uma perspectiva do Behaviorismo Radical, tem-se que o fair play não representa qualquer princípio universal e imutável ao qual se pode recorrer para certificar-se de que uma ação é necessariamente correta. Alguns comportamentos, característicos do esporte, estão valorados de forma mais organizada nas regras formais e fiscalizados por agências de controle. A existência de árbitros, por exemplo, que liberam consequências para os comportamentos dos atletas durante uma disputa é a representação clara das regras formalizadas. Associado à regulamentação formal, a noção de fair play, enquanto conjunto de valores dos membros envolvidos com a prática do esporte, permite avaliar situações novas e de conflito de valores, sem ter de recorrer a modificações nas regras formais, uma vez que, a noção de fair play, sob a ótica do Behaviorismo Radical, propõe regras mutáveis diante de situações novas (Morais, Melo \& Souza, no prelo).

Para os analistas do comportamento, os comportamentos são julgados como bons ou maus, como antiesportivo ou de fair play em razão dos efeitos das consequências sobre o comportamento e do sentimento, positivo ou negativo, que acompanha o efeito (Abib, 2001; Skinner, 1971/2002) nos três níveis de seleção (filogenético, ontogenético e cultural). Como afirmam Dittrich e Abib (2004, p. 427), nos três níveis seletivos "o comportamento produz certos efeitos, e é através destes efeitos que os problemas éticos devem ser analisados". Se as consequências fortalecem o comportamento e geram sentimentos positivos elas são valoradas como 
boas e, se as consequências têm efeitos enfraquecedores sobre o comportamento e produzem sentimentos negativos diz-se que elas são más.

Ainda, como afirmam Dittrich e Abib (2004), o comportamento ético define-se por sua relação com a produção de três tipos de bens - bens pessoais, bens dos outros e bens da cultura. Os bens pessoais referem-se aos reforçadores positivos em relação ao comportamento da pessoa que os produz, os bens dos outros aos reforçadores produzidos por um determinado indivíduo que resultam em reforço positivo para o comportamento de outras pessoas e, por fim, os bens da cultura que se referem às consequências de práticas culturais que contribuem para a sobrevivência da cultura que a promoveu. Contudo, estas consequências não são "mutuamente exclusiva[s] isto é, uma pessoa pode, através de certa ação, produzir não apenas um, mas dois ou três tipos de bens simultaneamente" (Dittrich \& Abib, 2004, p. 427). Como nem todos os comportamentos satisfazem as contingências seletivas em todos os níveis, é possível observar diferentes julgamentos de valor entre indivíduos, entre indivíduo e cultura, entre grupos de indivíduos e entre culturas diferentes (Skinner, 1971/2002).

Portanto, os valores podem mudar de acordo com as contingências sociais, assim como os comportamentos que produzem tais valores podem não ser sempre os mesmos (Skinner, 1971/2002). Compreender que os valores e comportamentos julgados como bons são mutáveis e dependem de inúmeras variáveis tem importantes implicações práticas. Possibilita compreender que indivíduos envolvidos com o esporte não são essencialmente antiesportivos ou esportivos. Os comportamentos, em particular os comportamentos de fair play, podem ser alterados e ensinados. As virtudes ou valores não são inerentes ao ser humano, por essa razão precisam ser aprendidos pelos mesmos princípios de aprendizagem dos demais comportamentos (Gomide, 2010). Assim, é possível pensar em formas estruturadas de promoção de comportamentos de fair play. Por exemplo, Del Pozo (2007) avaliou um modelo de intervenção para ensinar valores para crianças e jovens por meio do esporte. Para essa avaliação empregou o Instrumento de Observação de Fair Play no Futebol (IOOF). Os participantes, atletas de futebol das categorias benjamín (9 e 10 anos), alevín (11 e 12 anos), infantil (13 e 14 anos) e cadete (15 e 16 anos), foram distribuídos em duas condições (Grupos Controle e Experimental). A intervenção, realizada com o Grupo Experimental, consistiu em sessões semanais de 20 minutos, nas quais os treinadores abordavam com seus atletas os temas "jogo limpo" e "esportividade". Após a realização da intervenção, verificou-se que houve uma redução no número de faltas para a categoria benjamín e nos escores relacionados a comportamentos antiesportivos. Verificou-se, ainda, uma tendência a pontuações maiores para os comportamentos de fair play para todas as categorias que passaram pela intervenção.

Considerando-se que o fair play é o análogo da moralidade no esporte, citam-se pesquisas sobre comportamento moral desenvolvidas por analistas do comportamento (Gomide, 2010; Rocha, 2008). Gomide (2010), por exemplo, avaliou um programa de comportamento moral para crianças e adolescentes com problemas comportamentais. Os participantes foram designados para o Grupo Controle ou para o Grupo Experimental. Para avaliar a eficácia do programa foram usados três instrumentos: CBCL/6-18, Escala de Stress Infantil (ESI) e questionário de compreensão dos conteúdos. Para as crianças e adolescentes do Grupo Experimental foram realizadas sessões pré-definidas, em grupo, nas quais discutiram-se questões como pré-virtudes (polidez e obediência) e virtudes (empatia, amizade, mentira e verdade, honestidade, justiça e generosidade). Também foram trabalhados conceitos fundamentais para o desenvolvimento do comportamento moral e inibidores de comportamentos antissociais como a vergonha, a culpa, o perdão e a reparação do dano. Ao final do programa verificou-se, por meio do questionário de compreensão dos conteúdos, que os participantes do Grupo Experimental aprenderam os conteúdos do Programa de Comportamento Moral. Verificou-se, também, diminuição estatisticamente significativa no escore de cinco categorias do CBCL (problemas sociais, problemas de comportamento, problemas totais, transtorno compulsivo obsessivo e stress pós-traumático) e nos escores dos fatores de stress físico, psicológico e total para o Grupo Experimental, se comparado ao Grupo Controle.

Rocha (2008), por sua vez, avaliou procedimen- 
tos com foco na diminuição de comportamentos antissociais e engajamentos em comportamentos pró-sociais com adolescentes em conflito com a lei, internos. Os adolescentes participaram de sessões de psicoterapia analítico-comportamental. Os comportamentos terapêuticos mais utilizados durante as sessões foram, respectivamente, solicitar relato, informação, facilitação e empatia; enquanto os menos utilizados foram, reprovação, aprovação e recomendação. Os resultados indicaram que em nove dos 11 casos houve aumento na frequência de comportamentos adequados (auto-revelação, expressão de sentimentos positivos e expressão de arrependimento) e diminuição na frequência de comportamentos considerados inadequados como hostilidade, mentira e culpar o outro. Os resultados positivos obtidos por Gomide (2010) e Rocha (2008) sugerem a importância de intervenções para se promover classes de comportamento moral.

Pesquisadores como, Constantino (2002), Moreira e Pestana (2008) e Muñoz (2002), destacam a importância de um trabalho que envolva a prática esportiva e o ensino do fair play, principalmente na iniciação esportiva. Para tanto, ganha destaque os papéis dos agentes de socialização, que devem atuar fundamentados nas mesmas premissas. Os agentes de socialização têm importante papel na construção do ambiente esportivo (Valiente et al., 2001). Entre esses agentes destaca-se a figura do árbitro.

Arbitragem é um campo teórico que se compõem de um conjunto de regras e normas impressas em um código. $\mathrm{O}$ árbitro detém conhecimentos específicos sobre essas regras escritas e deve ter condições de interpretar os lances do jogo à luz das regras. Sua função, em esportes coletivos, é de compreender, interpretar e sancionar os lances (Becker, 2000). Segundo Betancor e Cabrera (1999), os árbitros são responsáveis por regular o processo esportivo e têm o compromisso de ensinar o regulamento durante as competições. Os árbitros fiscalizam e liberam consequências para os comportamentos dos atletas e, portanto, atuam como agências de controle no contexto esportivo, durante os jogos. As agências de controle são instituições como governo, educação, religião, economia. O tipo de classificação valorativa depende da agência de controle envolvida. Lícito/ ilícito são classificações comuns empregadas pelos governos e sistemas judiciários; pecado/virtude é empregado por sistemas religiosos; certo/errado por sistemas educacionais e esportivo/antiesportivo por organizações esportivas (Skinner, 1953/1965). No esporte, a FIFA, a Conmebol e a CBF são exemplos de agências controladoras.

Objetivando investigar o antiesportivismo e a violência que estão presentes em jogos de futebol de categorias de base, Gimeno et al. (2007) elaboraram uma pesquisa com treinadores e árbitros da Federação de Futebol de Zaragoza e de Vitoria, em que foi firmado um acordo de colaboração entre os treinadores dessas equipes e os presidentes da Federação e o Comitê de Árbitros, no qual se comprometiam a realizar uma série de atividades com o propósito de que na segunda rodada da competição não ocorressem incidentes violentos. Os resultados obtidos na segunda rodada da liga mostraram redução na frequência de comportamentos violentos, apontando a importância de intervenções dessa natureza.

No Brasil são poucas as pesquisas sobre fair play sendo que grande parte delas são estudos de revisão teórico-conceitual ou resgate histórico (e.g., Brito et al. 2011; Rubio \& Carvalho, 2005; Santos, 2005) e tradução e adaptação de inventário ou validação de questionário, direcionados apenas a atletas (e.g., Evangelista, 2011; Mazo, 2011). Verifica-se, portanto a necessidade de investigações sobre este tema principalmente com os responsáveis pela iniciação esportiva. Sendo assim, este trabalho teve por objetivo, por meio de uma ficha de avaliação, investigar o antiesportivismo e comportamento de fair play em jogos de futsal de categorias de base, a partir do relato da equipe de arbitragem dos jogos, correlacionando, ainda, as notas atribuídas pelos árbitros na ficha de avaliação ao número de faltas e cartões das partidas analisadas.

\section{Método}

\section{Participantes}

Participaram 17 árbitros de futsal que apitaram partidas da $1^{\text {a }}$ divisão do $10^{\circ}$ Campeonato Metropolitano de Futsal 2013, promovido pela Liga Metropolitana de Futsal de uma cidade do interior do Paraná. Esta pesquisa foi autorizada pelo Comitê de Ética em Pesquisas Envolvendo Seres Humanos (protocolo: 19463713.4.0000.5231). 


\section{Local}

A coleta de dados aconteceu nos ginásios esportivos nos quais as partidas foram realizadas.

\section{Materiais e Instrumentos}

Foram utilizadas a Ficha de Avaliação de Fair Play e a súmula das partidas.

\section{Ficha de avaliação de Fair Play}

Este instrumento foi desenvolvido por Gimeno et al. (2007), adaptado para o presente estudo. A Ficha é composta por duas partes. Na primeira registra-se o nome das equipes que jogaram, o resultado da partida, se o participante atuou como árbitro ou como treinador da equipe local ou da equipe visitante e a sua formação acadêmica. Na segunda parte há uma breve instrução de como a ficha deve ser preenchida e o que é entendido como comportamentos de fair play e antiesportivos. A instrução apresentada foi: "Você considerará que a partida foi muito esportiva caso tenham ocorrido muitos comportamentos de fair play (jogo limpo), como: cumprimentar o adversário, pedir desculpa por uma falta cometida, colocar a bola para fora quando um jogador estiver machucado etc. e considerará que a partida foi muito antiesportiva caso tenham ocorrido muitos comportamentos antiesportivos, como: faltas, agressões, não tirar a bola para fora quando há um jogador machucado, simular faltas etc.. Em seguida são apresentadas seis afirmações. São elas: (a) Você classificaria esse jogo como; (b) O treinador da equipe local, você classificaria como; (c) $\mathrm{O}$ treinador da equipe visitante, você classificaria como; (d) Os atletas da equipe local, você classificaria como; (e) Os atletas da equipe visitante, você classificaria como; (f) A atuação do árbitro contribuiu para que essa partida fosse.

Para cada afirmação há um valor a ser atribuído de zero a dez, sendo que para cada questão, 10 é considerado muito esportivo e zero, muito antiesportivo.

\section{Súmula}

A súmula do jogo é um documento padronizado confeccionado pela Confederação Brasileira de Futebol de Salão, porém, pode ser adaptado de acordo com as necessidades dos campeonatos. A súmula geralmente contém espaço para preenchi- mento das seguintes informações: nome das equipes; placar da partida; local da partida (cidade, estado e ginásio); horário do início e término do $1^{\circ} \mathrm{e}$ $2^{\circ}$ período; identificação do jogo (nome da competição, categoria, número do jogo, grupo, fase, data etc.); nome do técnico e do capitão; nome e número dos jogadores; cartões amarelos e vermelhos que cada jogador recebeu; gols feitos por cada jogador, número de faltas acumuladas no $1^{\circ}$ e $2^{\circ}$ período, por equipe; pedidos de tempo no $1^{\circ}$ e $2^{\circ}$ período, por equipe; dados da equipe de arbitragem [nome e registro dos árbitros 1 e 2 , anotador(a), cronometrista e delegado(a)]. No verso há espaço para anotações sobre a partida, e locais para assinatura dos representantes da arbitragem e das equipes.

\section{Procedimento}

Inicialmente realizou-se contato com o presidente da Liga Metropolitana de Futsal, que é responsável pela arbitragem dos campeonatos promovidos pela Liga, solicitando autorização para realização da coleta de dados durante os jogos da $1^{\text {a }}$ divisão do $10^{\circ}$ Campeonato Metropolitano de Futsal de 2013. Após a autorização, um e-mail foi encaminhado para a Liga que se encarregou de repassá-lo aos árbitros que participaram do campeonato.

A coleta de dados ocorreu da maneira descrita a seguir. Foram observados 20 jogos, sendo 11 jogos da categoria Sub 9 (em cada partida a duração era de dois tempos cronometrados de 10 minutos) e 9 jogos da categoria Sub 15 (cada partida com dois tempos cronometrados de 15 minutos). Ao final de cada partida foi entregue a equipe de arbitragem (árbitro principal, auxiliar e anotador) duas cópias do Termo de Consentimento Livre e Esclarecido (TCLE), uma via para o participante e outra via assinada, para a pesquisadora. Após a assinatura do TCLE foram entregues as Fichas de Avaliação de Fair Play seguidas de orientação oral sobre o preenchimento da mesma. Era dito "essa é a Ficha de Avaliação em que vocês deverão preencher seus dados: se você é treinador ou árbitro, sua formação e o tempo de formação. Deverão preencher também, os dados do jogo: quais são as equipes e o resultado da partida. Em seguida devem atribuir nota de 0 a 10 para as seis questões abaixo. Para cada questão será considerado muito esportivo, quando o valor atribuído for mais próximo de 10, e muito 
antiesportivo quanto mais próximo de zero." Após o preenchimento, as Fichas de Avaliação foram entregues para a pesquisadora.

Cópias das súmulas das partidas eram recolhidas com treinadores das equipes ao final dos jogos. Algumas súmulas, quando não foi possível recolher uma cópia com treinadores, foram obtidas diretamente com a Liga Metropolitana de Futsal ao final do campeonato.

\section{Análise dos dados}

Os dados obtidos por meio das Fichas de Avaliação de Fair Play e das súmulas das partidas foram tabulados e realizou-se análise estatística, sendo estas: Teste $t$ e Coeficiente de Correlação de Postos de Spearman, além da taxa de faltas e cartões por hora de jogo. O primeiro teste foi utilizado, pois permite avaliar as diferenças entre as médias de dois grupos, no caso desta pesquisa, média das questões das categorias Sub 9 e Sub 15, além de fornecer valor de significância de cada questão para essas duas categorias. O teste de Correlação de Spearman possibilitou averiguar se houve correlação entre a média das notas atribuídas pela equipe de arbitragem, referente à Questão 1, que avaliava a partida de modo geral, e a soma das faltas e cartões atribuídos nas partidas. O cálculo das taxas se deu a partir do número de faltas e cartões de cada categoria e da soma do tempo total em horas da duração das partidas de cada categoria. O cálculo das taxas permite equacionar a diferença do tempo que há entre as partidas de cada categoria.

\begin{tabular}{|c|c|c|c|c|c|c|c|c|c|c|}
\hline \multicolumn{11}{|c|}{ Sub 9} \\
\hline \multirow{2}{*}{ Jogo } & \multirow{2}{*}{ Partida } & \multirow{2}{*}{ Placar } & \multirow{2}{*}{ Faltas } & \multirow{2}{*}{ Cartões } & \multicolumn{6}{|c|}{ Média das notas } \\
\hline & & & & & Q1 & $\mathrm{Q} 2$ & Q3 & Q4 & Q5 & Q6 \\
\hline 1 & $A \times B$ & $02 \times 04$ & $3 \mid 3$ & Ol0 & 8,6 & 8,3 & 9,3 & 8,3 & 9 & 10 \\
\hline 2 & $C \times D$ & $00 \times 00$ & $2 \mid 4$ & 이1 & 8 & 8 & 8 & 8 & 8,3 & 9 \\
\hline 3 & $E \times C$ & $00 \times 02$ & $2 \mid 1$ & Ol0 & 10 & 8,6 & 9 & 9,6 & 9,6 & 10 \\
\hline 4 & $B \times F$ & $04 \times 02$ & 510 & Ol0 & 7 & 5,6 & 4,3 & 9,3 & 9,3 & 4,5 \\
\hline 5 & $C \times G$ & $06 \times 01$ & $1 \mid 3$ & 이1 & 9,6 & 9 & 9 & 9,6 & 8 & 10 \\
\hline 6 & $B \times D$ & $03 \times 01$ & 612 & Ol0 & 8,3 & 8,3 & 6,3 & 7,6 & 7,3 & 8,6 \\
\hline 7 & $\mathrm{C} \times \mathrm{F}$ & $06 \times 02$ & 이 1 & Ol1 & 7,3 & 8,6 & 8,6 & 8 & 7,3 & 9 \\
\hline 8 & $B \times F$ & $02 \times 00$ & $4 \mid 3$ & 110 & 10 & 10 & 10 & 10 & 10 & 10 \\
\hline 9 & $C \times D$ & $04 \times 02$ & 219 & 이2 & 8,3 & 8,3 & 7,6 & 9 & 9 & 8,3 \\
\hline 10 & $F \times D$ & $03 \times 03$ & $1 \mid 3$ & Ol0 & 9 & 9 & 9 & 9 & 9 & 9 \\
\hline 11 & $\mathrm{~B} \times \mathrm{C}$ & $05 \times 03$ & 710 & Ol0 & 9,3 & 9,3 & 9,3 & 9,3 & 9,3 & 9 \\
\hline \multicolumn{11}{|c|}{ Sub 15} \\
\hline \multirow{2}{*}{ Jogo } & \multirow{2}{*}{ Partida } & \multirow{2}{*}{ Placar } & \multirow{2}{*}{ Faltas } & \multirow{2}{*}{ Cartões } & \multicolumn{6}{|c|}{ Média das notas } \\
\hline & & & & & Q1 & Q2 & Q3 & Q4 & Q5 & Q6 \\
\hline 12 & $\mathrm{H} \times \mathrm{I}$ & $04 \times 06$ & $4 \mid 2$ & $2 \mid 3$ & 4,6 & 8 & 8 & 1,6 & 7 & 7,6 \\
\hline 13 & $\mathrm{~J} \times \mathrm{K}$ & $00 \times 02$ & 517 & 110 & 7 & 5,5 & 7,6 & 8 & 7,6 & 8,3 \\
\hline 14 & $\mathrm{~K} \times \mathrm{L}$ & $01 \times 01$ & $0 \mid 5$ & Ol0 & 8,3 & 8,3 & 8,3 & 8,3 & 8,3 & 9 \\
\hline 15 & $\mathrm{H} \times \mathrm{L}$ & $00 \times 00$ & 215 & Ol0 & 9,3 & 9,3 & 9,3 & 9,3 & 9,3 & 9,5 \\
\hline 16 & $I \times M$ & $01 \times 01$ & $4 \mid 3$ & $2 \mid 1$ & 8,3 & 8 & 8 & 8 & 8 & 8,5 \\
\hline 17 & LxI & $01 \times 03$ & $1 \mid 1$ & 110 & 8,6 & 8,6 & 8,3 & 7,6 & 8,3 & 10 \\
\hline 18 & $\mathrm{M} \times \mathrm{H}$ & $04 \times 01$ & $2 \mid 3$ & 111 & 8,6 & 8,3 & 8 & 7,3 & 7,6 & 9,3 \\
\hline 19 & $\mathrm{I} \times \mathrm{H}$ & $01 \times 05$ & $4 \mid 5$ & $1 / 2$ & 4,6 & 8,3 & 8,3 & 2,3 & 2 & 10 \\
\hline 20 & $L \times M$ & $01 \times 03$ & 212 & 110 & 8 & 7,3 & 8,3 & 6,6 & 8 & 9,5 \\
\hline
\end{tabular}

Nota: Q1 (Você classificaria esse jogo como); Q2 (O treinador da equipe local, você classificaria como); Q3 (O treinador da equipe visitante, você classificaria como); Q4 (Os atletas da equipe local, você classificaria como); Q5 (Os atletas da equipe visitante, você classificaria como); Q6 (A atuação do árbitro contribuiu para que essa partida fosse). 


\section{Resultados}

A Tabela 1 apresenta as médias das notas da equipe de arbitragem de cada partida na Ficha de Avaliação de Fair Play e dados da súmula das partidas (jogo, partida, placar, faltas e cartões) das categorias Sub 9 e Sub 15.

Observa-se que em todos os jogos da categoria Sub 9 ocorreram faltas. O jogo que apresentou menor número de faltas foi o Jogo 7, com apenas uma falta cometida pela equipe $\mathrm{F}$, e o jogo com maior número de faltas foi o Jogo 9, onze faltas, sendo duas faltas cometidas pela equipe $\mathrm{C}$ e nove pela equipe D. Quanto aos cartões apresentados durante os jogos desta categoria, pode-se considerar que houve baixa frequência de cartões (dos onze jogos realizados em apenas seis houve a apresentação de cartão), sendo que não houve apresentação de cartão vermelho em nenhuma das partidas. O Jogo 2, entre as equipes $\mathrm{C}$ e $\mathrm{D}$, foi o jogo em que o cartão foi apresentado mais vezes (duas).

Com relação às notas atribuídas pela equipe de arbitragem, nota-se que as menores médias foram atribuídas ao Jogo 4, em que ocorreram cinco faltas e nenhum cartão. $\mathrm{E}$ as maiores médias foram atribuídas ao Jogo 8 no qual ocorreram sete faltas e um cartão. Somente com a descrição desses dois jogos, é possível afirmar que a atribuição das notas não teve relação, necessariamente, com as faltas e cartões que ocorreram nos jogos, o que corrobora os dados apresentados pelo Teste de Correlação dos Postos de Spearman, que comparou a soma das faltas e cartões com as notas atribuídas pela equipe de arbitragem à Questão 1 (Você classificaria esse jogo como) em cada partida da categoria Sub 9. O valor de $p$ resultante deste teste $(0.8603)$ é considerado não significativo, apontando para a não existência de correlação entre o número de faltas e cartões com a avaliação feita pelo árbitro para a Questão 1 que avaliava a partida de maneira geral. A pontuação atribuída pelos árbitros a essa questão variou entre 7 e 10.

Ainda, em relação à Tabela 1 , observa-se que em todos os jogos da categoria Sub 15, assim como nos da categoria Sub 9, houve faltas. O Jogo 13 foi aquele em que houve um maior número de faltas (12 no total). O Jogo 17 foi aquele em que houve o menor número de faltas (duas). Com relação à apresentação de cartões, de um total de nove jogos, em sete deles houve a apresentação de cartões. Apenas nos Jogos 14 e 15 não houve a apresentação de cartões. Em nenhum dos jogos houve a apresentação de cartão vermelho. O total de cartões apresentados durante as partidas variou entre um (Jogo 13) e cinco (Jogo 12).

Referente às notas atribuídas pela equipe de arbitragem, os Jogos 12 e 19 foram os que obtiveram as menores médias referentes às seis questões da Ficha de Avaliação de Fair Play. Em ambos os jogos, o número de faltas e cartões foi alto (seis faltas e cinco cartões para o Jogo 12 e nove faltas e três cartões para o Jogo 19). O Jogo 15 foi o que recebeu maiores médias para as seis questões. Embora nenhum cartão tenha sido apresentado neste jogo, foram registradas sete faltas, sendo duas para a equipe $\mathrm{H}$ e cinco para a equipe $\mathrm{L}$.

\begin{tabular}{|c|c|c|c|c|}
\hline Questão & Categoria & Média & SD & $\mathrm{p}$ \\
\hline 1 & $\begin{array}{l}\text { Sub } 9 \\
\text { Sub } 15\end{array}$ & $\begin{array}{l}8,7 \\
7,48\end{array}$ & $\begin{array}{l}1,47 \\
2,28\end{array}$ & $0,0153^{*}$ \\
\hline 2 & $\begin{array}{l}\text { Sub } 9 \\
\text { Sub } 15\end{array}$ & $\begin{array}{l}8,48 \\
8\end{array}$ & $\begin{array}{l}1,33 \\
1,33\end{array}$ & 0,1647 \\
\hline 3 & $\begin{array}{l}\text { Sub } 9 \\
\text { Sub } 15\end{array}$ & $\begin{array}{l}8,24 \\
8,26\end{array}$ & $\begin{array}{l}1,87 \\
1,06\end{array}$ & 0,967 \\
\hline 4 & $\begin{array}{l}\text { Sub } 9 \\
\text { Sub } 15\end{array}$ & $\begin{array}{l}8,91 \\
6,59\end{array}$ & $\begin{array}{l}1,07 \\
2,82\end{array}$ & $0,0001^{*}$ \\
\hline 5 & $\begin{array}{l}\text { Sub } 9 \\
\text { Sub } 15\end{array}$ & $\begin{array}{l}8,76 \\
7,37\end{array}$ & $\begin{array}{l}1,23 \\
2,24\end{array}$ & $0,0035^{*}$ \\
\hline 6 & $\begin{array}{l}\text { Sub } 9 \\
\text { Sub } 15\end{array}$ & $\begin{array}{l}9 \\
9,09\end{array}$ & $\begin{array}{l}1,83 \\
0,93\end{array}$ & 0,9179 \\
\hline
\end{tabular}

Os dados obtidos com o Teste de Correlação dos Postos de Spearman, comparando a soma das faltas e de cartões com as notas atribuídas pela equipe de arbitragem à Questão 1, em cada jogo da categoria Sub 15, apresentou um valor de $p(p=0.0857)$, considerado não significativo, o que novamente indica 
a não existência de correlação entre o número de faltas e de cartões e a nota média atribuída pelos árbitros a cada questão. Quando se analisa o escore atribuído pelo árbitro a Questão 1 para cada jogo, verifica-se que para os Jogos 12 e 19 a nota média foi igual a 4,6, ou seja, estes dois jogos foram considerados pelos árbitros como aqueles que apresentaram menos fair play e mais comportamentos antiesportivos. Para os demais jogos as notas médias atribuídas variaram de 7 a 9,3.

A Tabela 2 apresenta os resultados da análise estatística a partir do Teste $t$, que objetivou avaliar as diferenças entre as médias das categorias Sub 9 e Sub 15 em cada questão, além de fornecer seus valores de significância.

No que diz respeito à Questão 1 (Você classificaria esse jogo como) encontraram-se diferenças significativas entre as categorias $(\mathrm{p}<0,0153)$. Sendo que o escore médio para esta questão foi menor para a categoria Sub 15, ou seja, de modo geral os árbitros avaliaram os jogos da categoria Sub 15 como mais antiesportivos.

Também foram encontradas diferenças significativas entre as categorias para a Questão 4 (Os atle- tas da equipe local, você classificaria como) e para a Questão 5 (Os atletas da equipe visitante, você classificaria como) com valor de $p<0,0001$ e $p<0,0035$, respectivamente. Novamente os escores médios atribuídos pela equipe de arbitragem foram menores para a categoria Sub 15 que para a categoria Sub 9, indicando que os árbitros avaliaram os atletas da categoria Sub 15 como apresentando menos comportamentos esportivos. Para as demais questões (2- O treinador da equipe local, você classificaria como; 3 - O treinador da equipe visitante, você classificaria como e 6A atuação do árbitro contribui para que essa partida fosse) não se verificou diferenças significativas.

A Tabela 3 apresenta a duração em horas, a quantidade de faltas e cartões de cada partida, além das respectivas somas totais para cada categoria (Sub 9 e Sub 15). Apresenta também a taxa de faltas/h e cartões/h.

Com relação à frequência de faltas, a categoria Sub 9 apresenta maior taxa que a categoria Sub 15 (10,21 faltas/hora e 8,51 faltas/hora, respectivamente). Porém, a categoria Sub 15 apresenta maior taxa de cartões que a categoria Sub 9 (2,39 cartões/hora e 0,99 cartões/hora, respectivamente).

Tabela 3 - Taxa, frequência absoluta de faltas e cartões e duração em horas das partidas das categorias Sub 9 e Sub 15.

\begin{tabular}{llllllll}
\hline Jogo & $\begin{array}{l}\text { Duração } \\
\text { (hora) }\end{array}$ & Faltas & Cartões & Jogo & $\begin{array}{l}\text { Duração } \\
\text { (hora) }\end{array}$ & Faltas & Cartões \\
\hline 1 & 0,45 & 6 & 0 & 12 & 0,72 & 6 & 5 \\
2 & 0,52 & 6 & 1 & 13 & 0,75 & 12 & 1 \\
3 & 0,53 & 3 & 0 & 14 & 0,75 & 5 & 0 \\
4 & 0,55 & 5 & 0 & 15 & 0,67 & 7 & 0 \\
5 & 0,58 & 4 & 1 & 16 & 0,78 & 7 & 3 \\
6 & 0,6 & 8 & 0 & 17 & 0,83 & 2 & 1 \\
7 & 0,57 & 1 & 1 & 18 & 0,67 & 5 & 2 \\
8 & 0,6 & 7 & 1 & 19 & 0,77 & 9 & 3 \\
9 & 0,58 & 11 & 2 & 20 & 0,77 & 4 & 1 \\
10 & 0,53 & 4 & 0 & & & & \\
11 & 0,55 & 7 & 0 & & & & 16 \\
Soma & 6,07 & 62 & 6 & Soma & 6,7 & 57 & 16 \\
total & & & total & & & \\
Taxa & - & 10,21 faltas/ & 0,99 cartões/ & Taxa & - & 8,51 faltas/ & 2,39 cartões/ \\
& & hora & hora & & & & hora \\
\hline
\end{tabular}




\section{Discussão}

Objetivou-se nesta pesquisa investigar a antiesportividade e os comportamentos de fair play, em jogos de futsal de categorias de base (Sub 9 e Sub 15), por meio de uma avaliação feita pela equipe de arbitragem. As notas atribuídas pelos árbitros foram correlacionadas, também, com as faltas e cartões das partidas. Com base nos resultados obtidos constatou-se a não existência de correlação entre a atribuição das notas pela equipe de arbitragem e a quantidade de faltas e cartões obtidos pelas equipes em cada jogo. A não correlação entre a avaliação do jogo feita pelo árbitro e o número de faltas e cartões pode ser uma consequência das características da própria modalidade, ou seja, espera-se que faltas e cartões ocorram em razão de o futsal ser um esporte de contato e da probabilidade de ocorrência desses eventos ser alta. Se faltas e cartões não são referência para a avaliação dos árbitros quanto ao fair play, suas avaliações poderiam estar sob controle de outros fatores como, por exemplo, o tipo de falta cometida, ocorrência ou não de agressões verbais ou físicas durante o jogo entre outros. O tipo de falta cometida não foi analisado nesse estudo e sugere-se que isso seja feito em pesquisas futuras na área. Um fato que pode corroborar essa hipótese, quando correlacionado com os dados, refere-se, a ocorrência de agressões físicas e verbais em um dos jogos das finais da categoria Sub 15 (Jogo 19: I x $\mathrm{H}$ ), envolvendo a equipe técnica de uma das equipes, os jogadores de ambas as equipes e, também, parte dos torcedores. O Jogo 12 entre as equipes $\mathrm{H}$ e I juntamente com o Jogo 19 obtiveram as menores médias, principalmente para a Questão 1 (Você classificaria este jogo como).

Em todos os jogos, de ambas as categorias, foram cometidas faltas. A frequência absoluta de faltas para a categoria Sub 9 foi de 62, enquanto que para a categoria Sub 15 a frequência absoluta de faltas foi de 57. A taxa de faltas ocorridas na categoria Sub 9 foi maior do que a taxa de faltas ocorridas na categoria Sub 15 (10,21 faltas/hora e 8,51 faltas/hora, respectivamente). Esse dado não corrobora a afirmação de Del Pozo (2008) sobre o fato de atletas mais velhos cometerem mais faltas do que os grupos de atletas mais jovens. Mas corrobora os dados de Morais (2014) que constatou, em pesquisa com atletas e treinadores, que os atletas de futsal da categoria Sub
9 cometeram mais comportamentos antiesportivos quando comparados à atletas da categoria Sub 15. Cabe ressaltar que ambos os estudos trabalharam com modalidades diferentes. No estudo de Del Pozo (2008) a modalidade investigada foi o futebol e no estudo de Morais (2014) a modalidade trabalhada foi o futsal. Regras específicas de cada modalidade podem ter contribuído para os resultados diferentes.

Com relação ao número de cartões, em aproximadamente $77 \%$ dos jogos da categoria Sub 15 houve a apresentação de cartões, com frequência de 2,39 cartões/hora. Para a categoria Sub 9 a porcentagem de jogos nos quais cartões foram apresentados foi de aproximadamente 55\%, com frequência de 0,99 cartões/hora. Nesta pesquisa, a frequência absoluta de faltas cometidas pelas equipes da categoria Sub 9 foi de 62 faltas e a frequência absoluta de cartões foi de 6 . Enquanto que para as equipes da categoria Sub 15, a frequência absoluta de faltas foi de 57 e de cartões foi de 16. Este dado sugere que houve maior frequência de faltas graves cometidas pelos atletas da categoria Sub 15 do que pelos atletas da categoria Sub 9. É possível, então, que a frequência de faltas graves em uma categoria tenha alguma correlação com a avaliação da arbitragem. Por outro lado, não foi encontrada essa correlação quando se analisam os dados da avaliação dos árbitros e o número de cartões de cada partida, individualmente. Ressalta-se que as instruções dadas aos árbitros não mencionavam o número de faltas ou cartões como um critério para que ele considerasse o jogo mais ou menos antiesportivo. É possível que a ausência de um critério dessa natureza tenha contribuído para os resultados observados. Estudos futuros poderiam investigar essa questão.

No referente às notas atribuídas pela equipe de arbitragem, as médias de três, das seis questões da Ficha de Avaliação de Fair Play, obtiveram diferenças significativas entre as categorias observadas. Sendo que para todas as questões o escore médio foi menor para a categoria Sub 15. Novamente, para os árbitros participantes desta pesquisa, os comportamentos de fair play ocorrem com menor frequência nos jogos da categoria Sub 15, quando comparados aos da Sub 9 corroborando a afirmação de Del Pozo (2008) segundo qual, a noção de fair play tende a ter seu significado diminuído frente à competitividade. 
Houve diferenças estatisticamente significativas entre as categorias, sendo que os atletas da Sub 9 foram avaliados como mais esportivos pelos árbitros. Não houve diferença estatística significativa com relação à avaliação dos árbitros dos atletas locais e visitantes. Diversos estudos discutem sobre a vantagem de se jogar em casa, tanto no futsal quanto em outros esportes de contato, como o futebol, basquete e vôlei. Porém, restringem-se a vantagem sobre a pontuação, demonstrando associação entre o fator local e resultado da partida, não abordando comportamentos antiesportivos ou de fair play (Almeida, Oliveira, \& Silva, 2011; Dickel, 2012; Silva, 2004).

Apesar de o futebol e o futsal serem esportes diferenciados, com regras próprias e diferenças na maneira de se jogar, muitos pais e treinadores consideram o futsal como a porta de entrada para o futebol. Por vezes o trabalho desenvolvido com crianças e adolescentes é conduzido embasado em modelos profissionais de alto rendimento (Cavichiolli, Cheluchinhak, Capraro, Marchi Junior, \& Mezzadri, 2011; Cruz et al., 1996; Del Pozo, 2008; Moreira \& Pestana, 2008). A imitação de modelos profissionais pelo esporte infantil tem levado treinadores, pais e torcedores a reproduzirem comportamentos apresentados nos esportes de alto rendimento como, por exemplo, insultos à equipe de arbitragem e pressão sobre o rendimento dos atletas (Del Pozo, 2008).

Em pesquisa, Gimeno et al. (2007) constataram que os comportamentos antiesportivos que mais ocorreram foram os de agressão verbal de pais para árbitros e entre os jogadores em campo, contudo, observou-se uma incidência de agressão física entre jogadores em campo (5\%) e entre pais e treinadores (4\%). Apesar de ser uma incidência baixa, chama-se a atenção para o impacto que pode trazer para a formação dos jovens esportistas frente a este cenário. Neste estudo não se pediu a equipe de arbitragem que avaliasse a participação dos torcedores no referente a comportamentos de fair play e antiesportivos. Considerando que a avaliação do jogo por eles pode ter levado em consideração o comportamento dos torcedores, esse tipo de investigação pode ser importante em estudos futuros. Questiona-se também se somente o relato verbal dos árbitros é uma medida confiável para investigação de comporta- mentos antiesportivos e de fair play, uma vez que eles podem estar envolvidos em condutas antiesportivas na própria atuação. Portanto, é importante que os dados obtidos a partir da arbitragem possam ser comparados com outras medidas, por exemplo, relatos verbais de treinadores e dados audiovisuais. O uso de dados audiovisuais é apontado por Gee (2011) como uma ferramenta que acrescenta informações à observação direta, pois possibilita que diversas variáveis possam ser consideradas, como por exemplo, o comportamento dos torcedores e da equipe técnica. Estudos futuros poderiam, com base nos dados obtidos, elaborar estratégias de intervenção para o fomento de comportamentos de fair play em atletas, pais, torcedores e treinadores, promovendo, por exemplo, cursos de capacitação.

Quando se trata de categorias de base, a participação dos pais neste contexto é fundamental. $\mathrm{Na}$ maioria das vezes eles são os torcedores presentes em quadras e estádios. Kidman, Mckenzie e Mckenzie (1999) e Gimeno (2006) afirmam que os pais podem depositar diferentes expectativas com relação ao futuro esportivo dos filhos, e muitas vezes suas ambições excedem as vontades dos mesmos, sendo este um fator de risco para o abandono da prática esportiva. Em estudo realizado por Kidman et al. (1999), em que foram analisados comentários feitos por pais em competições, constatou-se que a maioria dos comentários feitos pelos pais dirigia-se aos próprios filhos. Porém, os comentários não se restringiram somente aos filhos, eles foram direcionados também aos técnicos e árbitros. Os autores também constataram um alto índice de comentários considerados como negativos (corretivo, contraditório, irônico ou repressor) e instrutivos. Desta forma é importante ficar atento à participação dos pais no cenário esportivo, principalmente tratando-se de categorias de base.

\section{Considerações Finais}

Pela importância que a prática esportiva tem e considerando que sua iniciação está ocorrendo cada vez mais cedo, trabalhar os comportamentos de fair play pode contribuir para a formação do indivíduo. Os atores envolvidos no esporte de categorias de base podem contribuir para o aumento de comportamentos de fair play e na diminuição dos 
antiesportivos atuando tanto nas sessões de treinamento quanto nas competições (incentivando pedido e aceitação de desculpas; esclarecendo o regulamento; o que pode e não pode ser feito durante os jogos; ensinando comportamentos de fair play). Os árbitros podem contribuir para isso, atuando de forma clara, ensinando aos jogadores o regulamento e apontando as infrações cometidas, fornecendo regras claras e dispondo consequências de modo consistente. Para tanto, é importante compreender que os valores julgados como bons são mutáveis e que dependem de inúmeras variáveis. A partir desta compreensão, entende-se que os comportamentos, em particular os comportamentos de fair play, podem ser alterados e ensinados, possibilitando pensar em formas estruturadas de promoção de comportamentos de fair play, como, por exemplo, programar capacitações para árbitros, ou ainda alterar a forma de liberar consequências para os comportamentos nas partidas. Recentemente, a Série B italiana anunciou a implementação do cartão verde para premiar o comportamento esportivo (como jogar a bola para fora quando há um atleta machucado). A partir do cartão verde será criado um ranking, por meio do qual o jogador que obtiver mais cartões receberá uma premiação (Lance, 2015).

Segundo Guillén, Morán e Castro (1999), Marrero, Martín-Albo e Alonso (1999), o campo da arbitragem tem sido pouco explorado pela Psicologia do Esporte, apesar de ser composto por um grupo importante para a prática esportiva. Portanto, é importante que estudos investiguem a ocorrência de comportamentos de fair play e antiesportivos e contribuam para capacitações dos árbitros, principalmente os que atuam em competições de categorias de base, objetivando fomentar estas atitudes em atletas, pais e treinadores.

\section{Referências}

Abib, J. A. D. (2001) Teoria moral de Skinner e desenvolvimento humano. Psicologia: Reflexão Critica, 14 (1), 107-117. doi :10.1590/ S0102-79722001000100009

Almeida, L. G., Oliveira, M. L., \& Silva, C. D. (2011). Uma análise da vantagem de jogar em casa nas duas principais divisões do futebol profissional brasileiro. Rev. bras. Educ. Fís. Esporte, 25(1),
49-54. doi: http://dx.doi.org/10.1590/S180755092011000100006

Beckel, B. (2000). O árbitro esportivo. In: Beckel, B. Manual de Psicologia do Esporte e Exercício, (214-233). Porto Alegre: Novaprova.

Betancor, M. A. \& Cabrera, D. (1999). Objetivos del "Centro de Estudios del Arbitraje Deportivo" de la ULPGC. In: Guillén, F. La Psicología del Deporte en España al Final del Mileño, (567574). Gran Canaria: Servicio de Publicaciones y Producción Documental de la ULPGC.

Brito, S. M., Morais, J. V., \& Barreto, T. V. (2011). Regras de jogo versus regras morais: Para uma teoria sociológica do fair play. Revista Brasileira de Ciências Sociais. 26(75), 133-147. doi: http:// dx.doi.org/10.1590/S0102-69092011000100008

Cavichiolli, F., Cheluchinhak, A., Capraro, A., Marchi Junior, W., \& Mezzadri, F. (2011). O processo de formação do atleta de futsal e futebol: Análise etnográfica. Revista Brasileira de Educação Física e Esporte, 25(4), 631-647. doi: http://dx.doi.org/10.1590/rbefe.v25i4.16857

Constantino, M. T. (2002) A prática do fair play no contexto da culturalidade. In: Turini, $M$. \& Dacosta, L. Coletânea de textos em estudos olímpicos - Volume 1, (219-227) Rio de Janeiro: Editora Gama Filho.

Cruz J., Boixadós M., Valiente L., Torregrosa M., \& Mimbrero J. (1996) ¿Existe un deporte educativo?: Papel de las competiciones deportivas en el proceso de socialización del niño. Revista de Psicologia del Deporte, 9(10), 111-132.

Del Pozo, D. G. (2007) Modelo de intervención para educar en valores a través del fútebol: Una experiencia con entrenadores de fútebol de la comunidad de Madrid. (Tese Doutorado) Universidad Politécnica de Madrid. Madrid, Espanha. Retirado de oa.upm.es/6582/1/ DIEGO_GUTIERREZ_DEL_POZO.pdf

Del Pozo, D. G. (2008). El instrumento de observación de fair play en fútbol como herramienta para evaluar las conductas relacionadas con el juego limpio en jugadores jóvenes de fútbol. EduPsykhé: Revista de Psicología y Educación, 7(1), 61-79. Retirado de http://dialnet.unirioja. es/descarga/articulo/2696660.pdf.

Dickel, J. R. (2012). A influência do fator local de jogo no resultado final da partida na liga nacio- 
nal de futsal. (Trabalho de conclusão de curso - Graduação - Educação Física) - Universidade Federal do Rio Grande do Sul. Porto Alegre. Retirado de http://hdl.handle.net/10183/70273

Dittrich, A. \& Abib, J. A. D. (2004). O sistema ético skinneriano e consequências para a prática dos analistas do comportamento. Psicologia: Reflexão e Crítica, 17(3), 427-433. Retirado de http://www.scielo.br/ scielo.php?script $=$ sci_arttext $\&$ pid $=$ S0102$-79722004000300014 \& \operatorname{lng}=\mathrm{en} \& \mathrm{t} \operatorname{lng}=\mathrm{pt}$. 10.1590/S0102-79722004000300014

Estrada, C. J. A.; González-Mesa, C. G., \& Méndez, J. M. (2007). Participación en el deporte y fair play. Psicothema, 19 (1), 57-64. Retirado de http://www.psicothema.com/psicothema. asp?id=3328

Evangelista, P. H. M. (2011) As atitudes morais no esporte de competição: um estudo descritivo-exploratório com atletas dos jogos coletivos de invasão (Dissertação de Mestrado). Universidade Federal do Rio Grande do Sul. Porto Alegre, Rio Grande do Sul, Brasil. Retirado de http:// cev.org.br/biblioteca/as-atitudes-morais-esportecompeticao-um-estudo-descritivo-exploratorio-com-atletas-dos-jogos-coletivos-invasao/

Gee, C. J. (2011) Aggression in competitive sports: Using direct observation to evaluate incidence and prevention focused intervention. In: Luiselli, J. K., Reed, D. D. (Eds.), Behavioral Sport Psychology: Evidence-based approaches to performance enhancement. New York: Springer.

Gimeno, F. M. (2006). El trabajo en equipo de padres y entrenadores. Ikastaria, 15, 195-203. Retirado de http://www.euskomedia.org/ PDFAnlt/ikas/15/15195203.pdf.

Gimeno, F., Sáenz, A., Ariño, J., \& Aznar, M. (2007). Deportividad y violencia en el fútbol base: un programa de evaluación y prevención de partidos de riesgo. Revista de Psicología del Deport, 16(1), 103-118. Retirado de http://www.rpd-online.com/article/viewFile/25/25.

Gomide, P. I. C. (2010). Comportamento moral Uma proposta para o desenvolvimento das virtudes. Curitiba: Juruá.

Graziano, W. G. (1978). Standards of Fair Play in Same-Age and Mixed-Age Groups of Children. Developmental Psychology, 14, 524-
530. Retirado de http://psycnet.apa.org/index. cfm?fa=buy.optionToBuy\&id=1979-23383-001

Guillén, F., Morán, M., \& Castro, J. J. (1999). Consideraciones de carácter psicosocial sobre el arbitraje y el juicio deportivo. In: Guillén, F. La Psicología del Deporte en España al Final del Mileño, (583-591). Gran Canaria: Servicio de Publicaciones y Produccion Documental de la ULPGC.

Kavussanu, M., \& Boardley, I. D. (2009). The Prosocial and Antisocial Behavior in Sport Scale. Journal of Sport \& Exercise Psychology. 31, 97-117. doi: 10.1080/02640414.2013.775473

Kidman, L., Mckenzie, A., \& Mckenzie, B. (1999). The nature target of parents' comments during youth Sport competitions. Journal of Sport Behavior, 22, 54-68. Retirado de http://www. thefreelibrary.com/The+nature+and+target + of + parents $\% 27+$ comments+during+youth + spor t...-a054194987

Lance. (2015). Segunda divisão do italiano terá o uso do cartão verde. Retirado de http://esportes.terra.com.br/lance/segunda-divisao-do-campeonato-italiano-tera-uso-de-cartao-verd e,719b5e6a4ee45e9689271a3e28f782e3eqjlRC RD.html

Marrero, G., Martín-Albo, J., \& Alonso, J. L. N. (1999). Características del árbitro de fútbol y fútbol sala. In: Guillén, F. La Psicología del Deporte en España al Final del Mileño, (551556). Gran Canaria: Servicio de Publicaciones y Producción Documental de la ULPGC.

Mazo, J. Z. (2011). Os valores no esporte juvenil: um estudo com jovens participantes em projetos pró-sociais no município de Santo Ângelo, Rio Grande do Sul (Tese de Doutorado) Universidade Federal do Rio Grande do Sul. Porto Alegre, Rio Grande do Sul, Brasil. Retirado de http://www.lume.ufrgs.br/handle/10183/32730.

Morais, A. O. (2014). Comportamentos antiesportivos e de fair play: Análise do Comportamento aplicada à ética esportiva. Dissertação de Mestrado (Mestrado em Análise do Comportamento). Universidade Estadual de Londrina, Londrina.

Morais, A. O., Muchon, C., \& Souza, S. R. de. (no prelo). Uma Análise da ética esportiva a par- 
tir da Análise do Comportamento. Revista Brasileira de Terapia Cognitivo Comportamental.

Moreira, C. M. \& Pestana, G. D. (2008). Algumas reflexões sobre a Ética Desportiva. Motri., 4(3), 95-101. ISSN 1646-107X. doi: 10.6063/motricidade.4(3).276

Muñoz, A. P. (2002). Conducta Agresiva y Deporte. Cuadernos de Psicología del Deporte, 2(1), 3956. Retirado de http://revistas.um.es/cpd/article/view/105021

Pilz, G. A. (1995). Performace sport: education in fair play? Some empirical and theorical remarks. International Review for the Sociology of Sport, 30(3-4), 391-418. doi: $10.1177 / 101269029503000310$.

Rocha, G. V. M. (2008) Psicoterapia analítico-comportamental com adolescentes infratores de alto-risco: Modificação de padrões antissociais e diminuição de reincidência criminal. Tese de Doutorado, Programa de Pós-graduação em Psicologia Clínica, Universidade de São Paulo.

Rubio, K. \& Carvalho, A. L. (2005). Areté, fair play e o movimento olímpico contemporâneo. Revista Poruguesa de Ciência do Desporto, 5(3), 350-357. Retirado de http://www.scielo.gpeari.mctes.pt/scielo.php?pid=S1645$-05232005000300011 \&$ script=sci_arttext

Santos, A. R. R. (2005). Espírito esportivo - fair play e a prática de esportes. Revista Mackenzie de Educação Física e Esporte, 4(4), 13-28. Retirado de http://editorarevistas.mackenzie.br/index. $\mathrm{php} / \mathrm{remef} /$ article/view/1306/1012

Silva, C. D. A. (2004). Vantagem de Jogar em Casa: Uma Avaliação no Futebol Brasileiro na Temporada de 2003. Revista Digital, 10(71). Retirado de http://www.efdeportes.com/efd71/ emcasa.htm

Skinner, B. F. (1965). Science and human behavior. New York: The Free Press. (Original publicado em 1953).

Skinner, B. F. (2002). Beyond freedom and dignity. New York: Alfred A. Knopf. (Original publicado em 1971).

Valiente, L, Boixadós, M., Torregrosa, M., Figueroa, J., Rodríguez, M. A., \& Cruz J. (2001). Impacto de una campaña de promoción del fair-play y la deportividad en el deporte en edad escolar. Cuadernos de Psicología del Deporte, 1(1), 17 -
25. Retirado de www.unizar.es/...deporte/Fair_ Play_Jaume_Cruz.pdf

Weiss M. R., Smith, A. L., \& Stuntz, C. P. (2008). Moral development in Sport and Physical Activity. In T. S. Horne (Ed), Advances in Sport psychology (3). (188-210). Champaingn, II: Human Kinetics.

\section{Informações do Artigo}

Histórico do artigo:

Submetido em: 16/06/2015

Primeira decisão editorial: 05/09/2015

Aceito em: 07/10/2015 